\title{
Humerus distal interkondiler kırıklar
}

\section{Intercondylar fractures of the distal humerus}

\author{
Onur Bilge ${ }^{1}$, Mustafa Yel $\left.\right|^{1,2}$ \\ ${ }^{1}$ Konya Necmettin Erbakan Üniversitesi, Meram Tıp Fakültesi, \\ Ortopedi ve Travmatoloji Anabilim Dalı, Spor Hekimliği Anabilim Dalı \\ ${ }^{2}$ Konya Medline Hastanesi, Ortopedi ve Travmatoloji Bölümü
}

\begin{abstract}
Distal humerus kırıkları insan vücudundaki diğer kırıklar kadar sık görülmez. Çoğu zaman tanıları kolay, fakat tedavileri ve hangi tedavinin seçileceği zor olmaktadır. Bimodal bir yaş dağılımı gösteren bu kırıklarda, hem genç hem de yaşlı gruptaki farklılıklar tedavi planlanırken mutlaka göz önünde bulundurulmalıdır. Osteoporotik distal humerus kırıklarında, önümüzdeki yıllarda yaşlı popülasyonunda beklenen artış doğrultusunda, anlamlı bir artış yaşanacağı düşünüldüğünde tanıları kolay, fakat tedavileri tecrübe gerektiren bu kompleks kırıkların, tanı ve tedavilerinin doğru bir şekilde gerçekleştirilmesi önem kazanmaktadır. Bu makalede, distal humerus kırıkları hakkında temel bilgiler ve bu kırıklara klinik yaklaşım güncel literatür ışığında özetlenmiştir.
\end{abstract}

Anahtar sözcükler: humerus kırıkları; interkondiler; üst ekstremite; kemik kırıkları
Distal humerus fractures are not as frequently encountered as other fractures in the human body. Although their diagnosis is easy, the decision to choose the treatment method is not, and their treatment is difficult which mostly requires high level of experience. Confronted with these fractures which demonstrate a bimodal age distribution, the differences in both young and older patients should be taken into account while planning the treatment. Since a significant increase in osteoporotic distal humerus fractures is expected concordant with the increase in elderly population in the coming years, the realization of the correct diagnosis and treatment of these complex fractures demanding experience is extremely important. In this article, the basic information related with distal humerus fractures and clinical attitude to these cases were summarized according to the relevant and up-to-date literature.

Key words: humeral fractures; intercondylar, upper extremity; bone fractures
E rişkinlerde görülen distal humerus kırıklarının tedavisi, hızla gelişmekte olan implant teknolojileri ve cerrahi tekniklere rağmen çoğu zaman cerrahlar açısından zor olmaktadır. Ülkeden ülkeye değişmekle birlikte genel olarak, insan vücudunda görülen kırıkların \%1-7'sini ve dirsek çevresi kırıklarının yaklaşık \%30'unu distal humerus kırıkları oluşturmaktadır. ${ }^{[1-3]}$ Sıklıkları ile ilgili çok fazla çalışma bulunmamakla birlikte, Robinson ve arkadaşlarının yapmış olduğu bir epidemiyolojik çalışmada erişkinlerde sıklığı yıllık 100.000'de 5,7 olarak bildirilmiştir. ${ }^{[2]} \mathrm{Bu}$ bölgenin kırıkları; gençlerde genellikle yüksek enerjili bir travma sonrasında görülmesine rağmen, yaşlılarda sıklıkla düşme gibi düşük enerjili bir travma sonrasında görülür. ${ }^{[2]}$ Bimodal görülen bu yaş dağılımına koşut olarak, iki uç yaş grubundaki farklı beklentiler tedavi planlanırken mutlaka göz önünde bulundurulmalıdır. Erişkinlerde distal humerus kırıkları başlığı altında; suprakondiler kırıklar, tek kolon kırıkları, çift kolon kırıkları ve koronal makaslama kırıkları bulunmaktadır. En sık görülen tip her iki kolonun da etkilendiği interkondiler kırık tipidir. ${ }^{[4]}$

Osteoporotik distal humerus kırıklarında, önümüzdeki yıllarda yaşlı popülasyonunda, beklenen doğrultuda anlamlı bir artış yaşanacağı beklenmektedir. ${ }^{[5]}$ Bu bağlamda; tanıları kolay, fakat tedavileri tecrübe gerektiren bu kompleks kırıkların doğru bir şekilde ele alınması önem kazanmaktadır. Bu yazıda, erişkinlerde görülen distal humerus kırıklarının tanı ve tedavisi ile bu kırıklara yaklaşımda karşılaşılan zorluklar güncel literatür bilgileri doğrultusunda özetlenecektir.

- Illetişim adresi: Prof. Dr. Mustafa Yel, Konya Medline Hastanesi Ortopedi ve Travmatoloji Bölümü, Beyşehir Çevreyolu, Konya

Tel: nnnn-nnn nn nn e-posta: musyel@hotmail.com

- Geliștarihi: 10 Ocak2014 Kabul tarihi: 10 Ocak 2014 


\section{ANATOMI}

Distal humerus kırıklarının tanı ve tedavisinden önce, bu bölgenin anatomisinin çok iyi bilinmesi gereklidir. Dirsek eklemi tek hareket aksına sahip olan menteşeli bir eklemdir. Distal humerusun anatomisinde önemli bir yer tutan "Sütun Teorisi"nin, tedavi seçimi ve cerrahi yaklaşım için mutlaka akılda tutulması gereklidir. Bu teoriye göre, distal humerus lateral ve mediyal olmak üzere iki ana sütun ve bunları birbirine bağlayan, anatomik olarak trokleanın oluşturduğu "bağlı kemer"den oluşur. Dirsek ekleminin hareket aksı trokleadan geçer ki, bu nokta lateral ve mediyal kolonların birleşim yerini oluşturur. Troklear aks, $3-8^{\circ}$ dış rotasyonda bulunmaktadır. Yamaguchi ve ark. tarafindan yapılan ve bu teorinin oluşmasında önemli katkı sağlayan bir kadavra çalışmasında distal humerusun arteriyel kanlanmasına göre üç damarsal kemer tanımlanmıştır: lateral, mediyal ve posterior. ${ }^{[6]}$ Aynı konuda yapılmış bir diğer önemli çalışmada, distal humerusun kanlanmasında posterior damarların hakim olduğu gösterilmiştir. ${ }^{[7]}$ Dolayısıyla özellikle posterior girişimlerde, bu bölgenin periostunun korunması kaynamanın sağlanması açısından oldukça önemlidir. Humerusa ait intramedüller kanal, olekranon fossanın yaklaşık 2-3 cm üzerinde sonlanmaktadır.

\section{KLINIK DEĞERLENDIRME VE TANI}

Distal humerus kırığı olan hastaların ilk klinik değerlendirmesi genellikle acil serviste yapılır. Hastanın öyküsünde yaşın ve yaralanmanın oluş mekanizmasının öğrenilmesi, ek patolojilerin varlığının akla getirilmesi ve tedaviye yön verilmesi açısından çok önemlidir. Oluş mekanizmasını gençlerde yüksek enerjili darbeler, yaşlılarda düşük enerjili basit düşmeler oluşturmaktadır. Ayrıca dirseğin yaralanma anındaki pozisyonu da kırık tipini etkilemektedir. Dirsek $90^{\circ}$ fleksiyonda ise aksiyel yüklenme kolonlar arası bir kırığa, doğrudan posteriora çarpma olekranon kırı̆ı̆na ve/veya distal humerus kırığına yol açabilmektedir. Eğer yaralanma anında dirsek pozisyonu $90^{\circ}$ 'nin üzerinde bir fleksiyonda bulunuyorsa, bu pozisyon olası bir interkondiler kırığa neden olmaktadır. Ayrıca, yapılacak tedaviyi radikal bir şekilde değiştirebileceği için, özgeçmişte romatoid artritin olup olmadığı mutlaka sorgulanmalıdır.

Hastaya herhangi bir müdahale yapmadan önce, fizik muayenede yumuşak doku örtünmesinin ve vasküler durumun tespit edilip, nörolojik değerlendirmenin mutlaka yapılması gerekir. Kırığın açık kırık olduğunun görülmesi, yüksek enerjili bir travmayı akla getirir. Radyal ve ulnar nabızlara mutlaka bakılmalıdır. Eğer damar yaralanması da varsa, böyle bir durumda önceliği ekstremitenin acil olarak revaskülarizasyonu ve enfeksiyonun önlenmesi alır. En sık yaralanan sinir radyal sinir olmasına rağmen, daha seyrek de olsa ulnar ve median sinirler de yaralanabilir.

Acil servislerde çekilmesi gereken ilk grafiler, ön-arka ve yan dirsek grafileridir (Şekil 1). Fakat olguların çoğunda dirsekte şekil bozukluğu bulunduğu için, bu grafiler istenen ortogonal özellikte olmaz ve bu grafilerle kırık şeklinin ve parçalarının değerlendirmesi zordur. Humerusun proksimal ekleminin ve ön kolun distalinin de diyafiz ve dirsek eklemiyle birlikte görülmesi, ek patolojilerin atlanmaması açısından önemlidir.
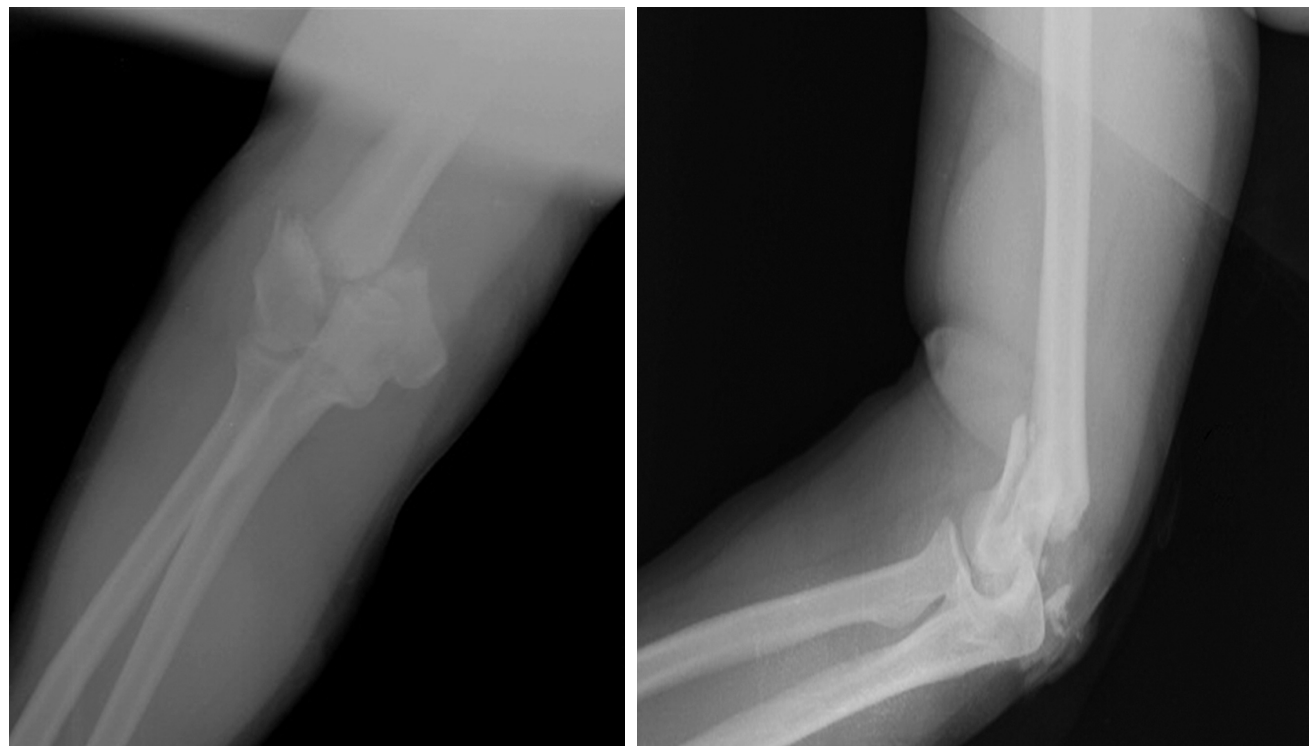

Şekil 1. Ön-arka ve yan dirsek grafilerinde görülen distal humerus AO-OTA Tip C çok parçalı kırı̆̆ı. 
Bilgisayarlı Tomografı (BT), kırık şeklinin daha iyi anlaşılması ve cerrahi öncesi planlamanın eksizsiz bir şekilde yapabilmesi için gereklidir. İki boyutlu BT, kırık hatları yönünde tekrar formatlanırsa oldukça faydalı bilgiler verir. Rekonstrükte edilmiş üç boyutlu $B T$ ise, radius ve ulnanın çıkartılmasıyla, humerus distalindeki kırıkların daha iyi görüntülenmesini sağlar. Bu yöntemin, kırıkların sınıflandırılmasında gözlemciler arası güvenilirliğinin yüksek olduğu gösterilmiş olmasına rağmen, ${ }^{[8]}$ son yıllarda tedavi sonuçlarının iyileştirilmesinde anlamlı katkısının olmadığı da ortaya konmuştur. ${ }^{[9]}$ Ameliyat öncesi en önemli görüntüleme yöntemlerinden birinin de, hasta genel anestezi aldıktan sonra, cerrahiye başlamadan önce çekilen traksiyon dirsek grafisi olduğu mutlaka akılda tutulmalıdır. ${ }^{[4]}$ Manyetik rezonans (MR) görüntüleme ise genellikle akut olgularda rutin olarak istenmez.

\section{SINIFLANDIRMA}

Distal humerus kırıklarının sınıflandırması günümüze kadar tanımlayıcı özellikte olmuştur: suprakondiler (olekranon fossanın üzerinde) kırıklar, transkondiler (olekranon fossa seviyesinde) kırıklar, interkondiler kırıklar, her iki kondilin kırığı, eklem yüzeylerinin kırıkları (kapitellum, troklea) veya epikondil kırıkları. ${ }^{[4,10]}$ Daha sonra farklı sınıflama yöntemleri tanımlanmış olsa da, ${ }^{[11,12]}$ günümüzde kabul görmüş evrensel sınıflama yöntemi olarak en sık AO-OTA (Association for Osteosynthesis - Orthopedic Trauma Association) sistemi kullanılır (Tablo 1). ${ }^{[13,14]}$

\section{TEDAVi}

Her geçen gün hızla gelişmekte olan implant teknolojilerine ve cerrahi tekniklere paralel bir şekilde, distal humerus kırıklarının birincil tedavisinde cerrahi standart hale gelmiştir. ${ }^{[11,15,16]}$ Günümüzde kabul gören birincil cerrahi tedaviler, açık yerleştirme ve içeriden tespit ile total dirsek artroplastisidir. Kurtarıcı cerrahilere (eksternal tespit, rezeksiyon artroplastisi, dirsek artrodezi) ise, genellikle ciddi kemik ve yumuşak doku kaybı veya enfeksiyon gibi durumlarda ikincil olarak ihtiyaç duyulur. ${ }^{[4]}$

Tablo 1. AO-OTA Sınıflama Sistemi - Distal Humerus Kırıkları (13-XX)

\begin{tabular}{ll}
\hline Tip & Özellik \\
\hline Tip A & Eklem dışı \\
Tip B & Kısmi eklem içi: tek sütunu ilgilendirir. \\
Tip C & Tam eklem içi: her iki sütunu da ilgilendirir. \\
\hline${ }^{*}$ Her üç tip kendi arasında kırık şeklinin kompleks oluşuna göre giderek \\
artan sırayla 1,2 ve 3 olacak şekilde alt tiplere ayrılmaktadır.
\end{tabular}

Alçı-atel, fonksiyonel breysleme ve "kemik torbası" gibi cerrahi dışı tedavilerin endikasyonları oldukça sınırlıdır. Konservatif tedaviler, 65 yaş üzerinde sadece seçilmiş olgularda (demans, serebrovasküler olay vs.) önerilebilir. ${ }^{[4]}$ Güncel literatürde, bu yaş grubundaki hastalardaki tedavi seçiminde, hastanın fonksiyonel durumunun kronolojik yaştan daha önemli olduğu da vurgulanmıştır. ${ }^{[17]}$

\section{Açık yerleştirme ve içeriden tespit}

Günümüzde distal humerus interkondiler kırıklarının cerrahi tedavi amaçları arasında dört önemli nokta yer alır:

1. Eklemin anatomik yerleştirme ve içeriden tespiti.

2. Aksiyel dizilimin sağlanması.

3. Distal eklem parçasının metafiz ve diyafize stabil içeriden tespiti.

4. Eklem sertliğinin önlenmesi için üç haftadan önce erken harekete başlanması.

Bu amaçları gözeterek hastalara yaklaşmak, ulaşılabilecek en iyi klinik sonuçların elde edilmesi için oldukça önemlidir. İmplant teknolojisinin ilerlemesine rağmen, bu amaçlara ulaşılması sırasında distal humerus kırıklarına özel bazı zorluklar karşımıza çıkar: bölgenin kompleks anatomisi, eklem ve metafizde parçalanma, özellikle yaşıılarda osteoporotik kemik varlığı. Ayrıca klinik sonuçları olumsuz etkileyen faktörler arasında; açık kırık, çoklu travma, çok parçalı eklem yüzeyi ve kemik kaybı sayılabilir. ${ }^{[18]}$

\section{Cerrahi yaklaşım}

Tüm eklem içi kırıklarda olduğu gibi interkondiler distal humerus kırıklarında da eklem redüksiyonunun anatomik olarak sağlanması, uzun dönem sonuçları olumlu yönde etkileyen en önemli etmenlerin başında yer alır. Dolayısıyla, eklemin anatomik olarak redükte olup olmadığından emin olmak, yapılacak cerrahi yaklaşımın doğru seçilmesi için gereklidir. Bu bağlamda doğru cerrahi yaklaşımın seçilmesi klinik sonuçları doğrudan etkiler. Açık redüksiyon için kullanılabilecek birçok cerrahi yaklaşım tanımlanmış olsa da en sık kullanılanlar şunlardır ${ }^{[19]}$ : olekranon osteotomileri (transvers ve Chevron), trisepsi bölen ("triceps-splitting"), trisepsi kaldıran Bryan-Morrey ("triceps-reflecting"), para-trisipital ("triceps-on"). Dirsek eklemine yapılacak posterior cerrahi girişimler ayrı bir konu başlığı olduğu için, bu bölümde cerrahi yaklaşımların teknik ayrıntılarından çok güncel literatürün özeti sunulmuştur.

Wilkinson ve Stanley tarafindan yapılan anatomik bir çalışmada, bu bölgede sık kullanılan posterior yaklaşımlar, eklem yüzeylerinin göründügüü miktarlar 
açısından karşılaştırılmıştır. ${ }^{[20]}$ Bu miktarlar yüzde olarak olekranon osteotomisi, trisepsi kaldıran ve trisepsi ayıran yaklaşımlar için sırasıyla; $\% 57, \% 46$ ve $\% 35$ olarak bulunmuştur. Dolayısıyla olekranon osteotomisinin, distal humerus kırıklarının içeriden tespitinde en iyi görüşü ve yaklaşımı sağladığı gösterilmiştir. Bu avantajına rağmen, kaynamama, yanlış kaynama, semptomatik implant ve eğer ameliyat sırasında total dirsek artroplastisine geçmek gerekirse teknik zorluklar gibi dezavantajları bulunur. Olekranon osteotomisi eklem içi bir osteotomidir ve sağladığı geniş görüş açısı nedeniyle AO-OTA Tip $C$ distal humerus kırıklarının çoğunda tercih edilen yaklaşımdır. ${ }^{[21]}$

Günümüze kadar tanımlanmış yaklaşımların her birinin kendi avantaj ve dezavantajları bulunmaktadır. Ljungquist ve arkadaşlarının yaptı̆̆ı güncel bir özet çalışmada; distal humerusa yapılan farklı yaklaşımların fonksiyonel sonuçlarını karşılaştıran ileriye dönük, randomize çalışmaların eksikliği ve dirsek sonuç ölçütlerinin yetersizliği nedeniyle, bir tekniğin diğerine üstün olduğunu söyleyebilmenin çok zor olduğu vurgulanmıştır. ${ }^{[19]}$ Ayrıca yine aynı özette değerlendirilen çalışmalarda, gruplar arasında anlamlı farklılığa rastlanmadığı belirtilmiştir.

\section{Tespit}

Evre 3 açık distal humerus kırıklarında geçici veya kalıcı eksternal tespit önerileceği gibi, yaşlı hastalarda da halka tespit uygulaması ile ilgili başarılı sonuçlar bildirilmiştir. ${ }^{[22]}$ Bu durumlar dışında distal humerus kırıklarının tespitinde en sık kullanılan yöntem plakvida uygulamasıdır. Plak uygulamasında amaç, her iki kolonun stabilizasyonunu sağlamaktır. Bu amaç, ya $90-90$ ortogonal plaklama ya da paralel plaklama teknikleri ile yapılabilmektedir. Distal humerus kırıklarında stabil tespitin sağlanması gerektiği konusunda artık bir fikir birliği olsa da, hangi teknik ile tespitin yapılacağı ile ilgili tartışmalar sürmektedir. Ancak, bu iki plaklama tekniğinden hangisinin daha üstün olduğu ile ilgili tartışmalar sürüyor olsa da, son yıllarda yapılan kanıt düzeyi yüksek çalışmalarda paralel plaklamanın ortogonal plaklamaya göre biyomekanik olarak daha stabil bir tespit sağladığı ve fonksiyonel sonuçlarının erken harekete izin verecek kadar yeterli olduğu gösterilmiştir. ${ }^{[23-25]}$ Paralel plak uygulamasının başarıya ulaşması için O'Driscoll tarafından tanımlanan kuralların yerine getirilmesi, başarılı klinik sonuçların da anahtarını oluşturur. ${ }^{[26,27]}$ Bu kurallar Tablo 2'de özetlenmiştir. Üçüncü bir plak, ciddi parçalanması ve instabilitesi olan durumlarda veya eşlik eden koronal plandaki kırık fragmanlarının tespiti için eklenebilir. ${ }^{[28]}$

\section{Dirsek artroplastisi}

Distal humerus kırı̆̆ının genç hasta grubundaki cerrahi tedavisinde birincil artroplastinin endikasyonu bulunmamakla birlikte, açık yerleştirme ve içeriden tespit standart tedavi yöntemi olarak kabul görmüştür. $[4,10,27,29]$ Akut dirsek kırıklarında total dirsek artroplastisinin kullanımı ile ilgili klinik sonuçlar ilk kez, çoğu romatoid artrit tanısı alan hastaları içeren Cobb ve Morrey tarafından yapılan "premier” çalışmada 1997'de bildirilmiştir. ${ }^{[30]}$ Dirsek artroplastisinde kullanılabilecek cerrahi yaklaşım seçenekleri, açık yerleştirme ve içeriden tespitten farklı olarak daha sınılıdır: trisepsi ayıran "tricepssplitting” veya paratrisipital "triceps-on" yaklaşımlar.

Bu konuda günümüze kadar yapılmış çalışmalar incelendiğinde; ortalama yaşları 69-85 olan hastalara uygulanan akut dirsek artroplastisinin ortalama 1,5-7 yıllık takiplerinde ortalama Mayo dirsek performans skorlarının 90'ın üzerinde, revizyon oranlarının \%0-23 ve komplikasyon oranlarının ise \%0-29 arasında olduğu görülür. ${ }^{[31,32]}$

Hemiartroplastinin kullanımının, total dirsek artroplastisine alternatif olacak şekilde kısa dönem iyi sonuçları bildirilmiş olmasına rağmen, bu uygulama FDA (Food and Drug Administration) onayını henüz almamıştır. ${ }^{[33]}$

\section{Tedavi seçimi}

Tedavi seçimleri ile ilgili olarak günümüze kadar yapılmış en kapsamlı literatür özeti 2013 yılında Wang

Tablo 2. O'Driscoll tarafından tarif edilmiş ve distal humerus kırıklarında uygulanan paralel plak uygulamasının başarılı olması için dikkat edilmesi gereken kurallar. ${ }^{[26]}$

- Distal parçadaki her vida plaktan geçmelidir.

- Plaktan geçen her vida karşı taraftaki parçayı da tutmalıdır.

- Distal parçaya mümkün olduğu kadar çok vida yerleştirilmelidir.

- Bütün vidalar mümkün olduğunca uzun olmalıdır.

- Her vida olabildiğince çok eklem parçasından geçerek onları tutmalıdır.

- Distal parçadaki vidalar sabit açılı bir yapı oluşturarak, birbirine geçerek kilitlenmelidir.

- Plaklar, her iki kolonun suprakondiler seviyesinde kompresyon yapacak şekilde uygulanmalıdır.

- Plaklar, suprakondiler seviyede kaynama olmadan önce kırılmaya ve bükülmeye direnç gösterecek kadar güçlü ve bükülmez olmalıdır. 
ve arkadaşları tarafından yapılmış olan Cochrane metaanalizidir. ${ }^{[34]} \mathrm{Bu}$ özetin sonucunda, distal humerus kırıklarının tedavisinde en iyi yöntemin hangisi olduğu ile ilgili literatürde yeterli yüksek düzey kanıtın bulunmadığı belirtilmiştir. Fakat, bimodal dağılım gösteren distal humerus kırıklarında tedavi seçiminin cerrahlar açısından daha kolay hale getirilmesi için Mehlhoff ve Bennett tarafından 2011 yılında, kolay uygulanabilir, önemli bir algoritma ortaya konulmuştur. ${ }^{[4]}$

Bu algoritmaya göre genç erişkinler, "kesinlikle tespit yapılması gereken grup" olarak tanımlanmıştır ve Evre 3 açık kırıkların ilk acil müdahalesi dışında bu hastalara "açık yerleştirme ve içeriden tespit" yapılması gereklidir.

Altmış beş yaş ve üzeri yaşlı hastalar ise üç gruba ayrılmaktadır: "tespit edilebilen", "tespit edilemeyen" ve "tespit edilmemesi gereken". Kemik kalitesi ve stoğu yeterli ise, "tespit edilebilen" hasta grubuna "açık yerleştirme ve içeriden tespit" başarılyla uygulanabilir. Eğer takiplerinde yetmezlik veya kaynamama meydana gelirse, total dirsek artroplastisine geçilebilir. Çok parçalanmış, alçak transkondiler ve osteoporotik kırı̆ı olan "tespit edilemeyen" hasta grubuna çoğunlukla birincil total dirsek artroplastisi, seyrek olarak da hemiartroplasti uygulanabilir. Önceden romatoid artrit gibi inflamatuvar artriti olan "tespit edilmemesi gereken" hasta grubunda ise birincil tedavi olarak total dirsek artroplastisi seçilmelidir.

Son olarak; günümüze kadar kanıt düzeyi en yüksek çalışma, çok merkezli, prospektif, randomize ve kontrollü olarak McKee ve arkadaşları tarafından 2009 yılında gerçekleştirilmiştir. ${ }^{[35]}$ ileri yaşı hastalarda yapılan bu çalışmada; birincil ve ikincil total dirsek artroplastisi yapılan hastalar arasında klinik sonuçlar ve komplikasyonlar açısından fark bulunmamıştır. Fakat, birincil açık yerleştirme ve içeriden tespit yapılan hastaların \%25'inde daha sonra total dirsek artroplastisine geçilmiş olması dikkat çekicidir (Şekil 2).
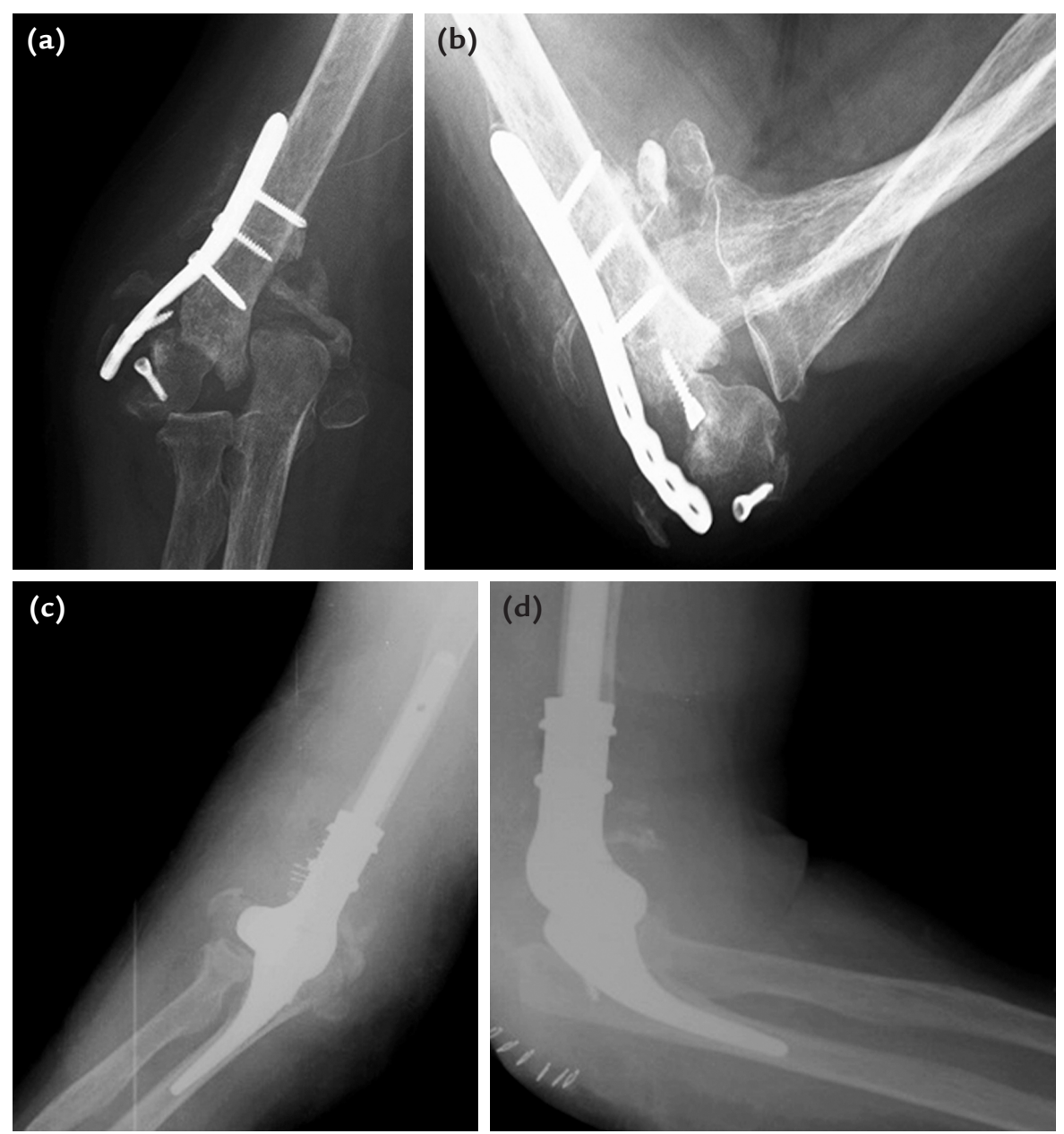

Şekil 2. a-d. Altmış yedi yaş, kadın hastaya ait grafiler. Düşme sonrasında distal humerus kırığı sonrasında dış merkezde açık yerleştirme ve internal tespit yapılmasından 8 ay sonra implant yetmezliği gelişimi $(\mathbf{a}, \mathbf{b})$. İmplantların çıkartılmasından sonra total dirsek protezi uygulaması (c, d) (Dr. O. Bilge'nin arşivi). 
Standart cerrahi sonrası bakım dışında, distal humerus kırıklarında stabil bir tespit ve yeterli yumuşak doku örtünmesi sağlandıktan sonra, ağrı kontrolü için kısa bir süre alçı desteği ve basit omuz askısı kullanılabilir. Tespitin stabilitesine koşut olarak birkaç gün içinde erken harekete (özellikle aktif yardımlı ve aktif eklem hareket açıklığı) başlanması, eklemde katılık ve hareket kısıtlığını önlemek için önemlidir. Heterotopik ossifikasyon riskinin yüksek olduğu hastalarda antiinflamatuvar ilaçlar veya radyoterapi seyrek de olsa önerilebilir.

Açık yerleştirme ve içeriden tespit yapılan hastalara ameliyat sonrası 6-12 hafta herhangi bir ağır yük kaldırmamaları da hatırlatılmalıdır. Ayrıca total dirsek artroplastisi yapılan hastaların tekrarlayan yük kaldırmalarında $2,3 \mathrm{~kg}$ ve tek seferde ise $4,5 \mathrm{~kg}$ sınırlamasının hayat boyu olduğu unutulmamalıdır. ${ }^{[34]}$

\section{Komplikasyonlar}

Distal humerus kırıkları sonrasında görülen, şikayet yaratan en sık komplikasyon, ağrılı, ciltten belirgin hale gelen implantlardır. ${ }^{[34]}$ En sık olekranonda görülen bu durumda, kırık iyileştikten sonra implantlar çıkartılır ve hastaya 6-12 hafta ağır yük kaldırmamaya özen göstermesi önerilir. Diğer görülebilecek komplikasyonlar arasında; ulnar sinir yaralanması, tespitin kalitesinin bozulması, eklem hareketinin kaybı, kaynamama, enfeksiyon, dirsek osteoartriti ve heterotopik ossifikasyon yer alır. Ulnar sinir nörapraksisi nedenleri arasında cerrahi sırasındaki ekartasyon, implantın basısı veya yetersiz serbestleştirme sayılabilir. Literatürde ulnar sinirin anteriora transpozisyonu ile ilgili bu görüşü destekleyen veya desteklemeyen yayınlar vardır. ${ }^{[36,37]}$ Vazquez ve arkadaşları tarafından yapılan güncel bir çalışmada, ulnar sinir transpozisyonunun yararlı olup olmadığının tespit edilmesi ve rutin olarak önerilebilmesi için ileriye dönük randomize, gücü yüksek çalışmaların gerekli olduğu vurgulanmıştır. ${ }^{[38]}$ Kırık hattında kaynamama, genellikle kırık hattında değil olekranon osteotomi hattında görülür. Eğer kırık hattında kaynamama görülürse, genellikle tespit yetmezliğine ikincil olarak gelişir. Bu durumda kemik greftlemesi ile plaklamada revizyon yapılması önerilir. ${ }^{[4]}$ En sık görülen hareket kısıtlılığı ekstansiyon kısıtlılığı olsa da, klinik sonuçlarının iyi olduğu bildirilmiştir. ${ }^{[28,39]}$

\section{KAYNAKLAR}

1. Court-Brown CM, Caesar B. Epidemiology of adult fractures: a review. Injury 2006;37(8):691-7.

2. Robinson CM, Hill RM, Jacobs N, Dall G, Court-Brown CM. Adult distal humeral metaphyseal fractures, epidemiology and results of treatment. J Orthop Trauma 2003;17(1):38-47.

3. Anglen J. Distal humerus fractures. J Am Acad Orthop Surg 2005;13(5):291-7.
4. Mehlhoff TL, Bennett JB. Distal humeral fractures: fixation versus arthroplasty. J Shoulder Elbow Surg 2011;20(2 Suppl):S97-106. CrossRef

5. Palvanen M, Kannus P, Niemi S, Pakkari J. Secular trends in osteoporotic fractures of the distal humerus in elderly women. Eur J Epidemiol 1998;14(2):159-64.

6. Yamaguchi K, Sweet FA, Bindra R, Morrey BF, Gelberman RH. The extraosseous and intraosseous arterial anatomy of the adult elbow. J Bone Joint Surg Am 1997;79(11):1653-62.

7. Kimball JP, Glowczewskie F, Wright TW. Intraosseous blood supply to the distal humerus. J Hand Surg Am 2007;32(5):642-6.

8. Doornberg J, Lindenhoivius $A$, Kloen $P$, van Dijk CN, Zurakowski D, Ring D. Two and three-dimensional computed tomography for the classification and management of distal humeral fractures. Evaluation of reliability and diagnostic accuracy. J Bone Joint Surg Am 2006;88(8):1795-801.

9. Brouwer KM, Lindenhovius AL, Dyer GS, Zurakowski D, Mudgal CS, Ring D. Diagnostic accuracy of 2- and 3-dimensional imaging and modeling of distal humerus fractures. J Shoulder Elbow Surg 2012;21(6):772-6. CrossRef

10. Clarke AM, Amirfeyz R. Distal humerus fractures - where are we now? Orthopaedics and Trauma 2012;26(5):303-9. CrossRef

11. Riseborough EJ, Radin EL. Intercondylar $T$ fractures of the humerus in the adult. A comparison of operative and nonoperative treatment in twenty-nine cases. J Bone Joint Surg Am 1969;51(1):130-41.

12. Jupiter JB, Mehne DK. Fractures of the distal humerus. Orthopedics 1992;15(7):825-33.

13. Marsh JL, Slongo TF, Agel J, BroderickJS, Creevey W, DeCoster TA, Prokuski L, Sirkin MS, Ziran B, Henley B, Audigé L. Fracture and dislocation classification compendium - 2007: Orthopaedic Trauma Association Classification, database and outcomes committee. J Orthop Trauma 2007;21(10 Suppl):S1-133.

14. Mueller ME, Nazarian S, Koch P, Schatzker J. Comprehensive classification of fractures of long bones. Berlin, Germany: Springer-Verlag; 1990.

15. Wong AS, Baratz ME. Elbow fractures: distal humerus. J Hand Surg Am 2009;34(1):176-90. CrossRef

16. Galano GJ, Ahmad CS, Levin WN. Current treatment strategies for bicolumnar distal humerus fractures. J Am Acad Orthop Surg 2010;18(1):20-30.

17. Pidhorz L, Alligand-Perrin P, De Keating E, Fabre T, Mansat P; Société française de chirurgie orthopédique et traumatologie (SoFCOT). Distal humerus fracture in the elderly: Does conservative treatment still have a role? Orthop Traumatol Surg Res 2013;99(8):903-7. CrossRef

18. Kundel K, Braun W, Wieberneit J, Rüter A. Intraarticular distal humerus fractures. Factors affecting functional outcome. Clin Orthop Relat Res 1996:(332):200-8.

19. Ljungquist KL, Beran MC, Awan $H$. Effects of surgical approach on functional outcomes of open reduction and internal fixation of intra-articular distal humerus fractures: a systematic review. J Shoulder Elbow Surg 2012;21(1):12635. CrossRef

20. Wilkinson JM, Stanley D. Posterior surgical approaches to the elbow: a comparative anatomic study. J Shoulder Elbow Surg 2001;10(4):380-2.

21. Pollock JW, Athwl GS, Steinmann SP. Surgical exposures for distal humerus fractures: a review. Clin Anat 2008;21(8):75768. CrossRef 
22. Burg A, Berenstein M, Engel J, Luria T, Salai M, Dudkiewicz I, Velkes S. Fractures of the distal humerus in elderly patients treated with a ring fixator. Int Orthop 2011;35(1):101-6. CrossRef

23. Stoffel K, Cunneen S, Morgan R, Nicholls R, Stachowiak G. Comparative stability of perpendicular versus double-locking plating systems in osteoporotic comminuted distal humerus fractures. J Orthop Res 2008;26(6):778-84. CrossRef

24. Atalar AC, Demirhan M, Salduz A, Kiliçoğlu O, Seyahi A. Functional results of the parallel-plate technique for complex distal humerus fractures. Acta Orthop Traumatol Turc 2009;43(1):21-7. CrossRef

25. Zalavras CG, Vercillo MT, Jun BJ, Otarodifard K, Itamura JM, Lee TQ. Biomechanical evaluation of parallel versus orthogonal plate fixation of intra-articular distal humerus fractures. J Shoulder Elbow Surg 2011;20(1):12-20. CrossRef

26. O'Driscoll SW. Optimizing stability in the distal humerus fracture fixation. J Shoulder Elbow Surg 2005;14(1 Suppl S):186S-94S.

27. Sanchez-Sotelo J, Torchia ME, O’Driscoll SW. Complex distal humeral fractures: internal fixation with principle-based parallel-late technique. Surgical technique. J Bone Joint Surg Am 2008;90 Suppl 2 Pt 1:31-46. CrossRef

28. Gofton WT, Mcdermid JC, Patterson SD, Faber KJ, King GJ. Functional outcome of $A O$ type $C$ distal humerus fractures. J Hand Surg Am 2003;28(2):294-308.

29. Sanchez-Sotelo J, Morrey BF. Total elbow arthroplasty. J Am Acad Orthop Surg 2011;19(2):121-5.

30. Cobb TK, Morrey BF. Total elbow arthroplasty as primary treatment for distal humeral fractures in elderly patients. J Bone Joint Surg Am 1997;79(6):826-32.

31. Gambriasio R, Riand N, Stend R, Hoffmeyer P. Total elbow replacement for complex fractures of the distal humerus. An option for the elderly patient. J Bone Joint Surg $\mathrm{Br}$ $2001 ; 83(7): 974-8$.
32. Kamineni S, Morrey BF. Distal humeral fractures treated with noncustom total elbow replacement. J Bone Joint Surg Am 2004;86-A(5):940-7.

33. Adolfsson L, Hammer R. Elbow hemiarthroplasty for acute reconstruction of intraarticular distal humerus fractures: a preliminary report involving 4 patients. Acta Orthop 2006;77(5):785-7.

34. Wang $Y$, Zhuo Q, Tang $P$, Yang W. Surgical interventions for treating distal humerus fractures in adults. Cochrane Database Syst Rev 2013;1:CD009890. CrossRef

35. McKee MD, Veillette CJ, Hall JA, Schemitsch EH, Wild LM, McCormack R, Perey B, Goetz T, Zomar M, Moon K, Mandel S, Petit S, Guy P, Leung I. A multicenter, prospective, randomized, controlled trial of open reduction-internal fixation versus total elbow arthroplasty for displaced intraarticular distal humeral fractures in elderly patients. J Shoulder Elbow Surg 2009;18(1):3-12. CrossRef

36. Wang KC, Shih HN, Hsu KY, Shih $\mathrm{CH}$. Intercondylar fractures of the distal humerus: routine anterior subcutaneous transposition of the ulnar nerve in a posterior operative approach. J Trauma 1994;36(6):770-3.

37. Chen RC, Harris DJ, Leduc S, Borrelli JJ Jr, Tornetta P 3rd, Ricci WM. Is ulnar nerve transposition beneficial during open reduction internal fixation of distal humerus fractures? J Orthop Trauma 2010;24(7):391-4. CrossRef

38. Vazquez $O$, Rutgers $M$, Ring DC, Walsh M, Egol KA. Fate of the ulnar nerve after operative fixation of distal humerus fractures. J Orthop Trauma 2010;24(7):395-9. CrossRef

39. Huang TL, Chiu FY, Chuang TY, Chen TY. The results of open reduction and internal fixation in elderly patients with severe fractures of the distal humerus: a critical analysis of the results. J Trauma 2005;58(1):62-9. 